\title{
Metalurgia y hábitat en el País Vasco de epoca medieval: el asentamiento ferrón de Bagoeta, Álava (ss.VII-XIV d.C.)
}

\author{
Metallurgy and habitat in the Basque Country of medieval time: the iron \\ settlement of Bagoeta, Álava (7th - I4th c. A.D.)
}

\author{
Agustín Azkarate Garai-Olaun* \\ José Manuel Martínez Torrecilla*** \\ José Luis Solaun Bustinza**
}

\begin{abstract}
RESUMEN
Dado que el notable volumen de información generado por la intervención arqueológica efectuada en el asentamiento de Bagoeta está aún en proceso de estudio, los resultados que se presentan en este artículo no son sino un avance que, no obstante, nos permite constatar con seguridad la existencia de un asentamiento en el que se han detectado dos sectores de ocupación distantes entre sí unos 500 metros. El primero de ellos funcionó durante una horquilla cronológica que transcurre entre los siglos VII y VIII d.C., poseyendo un carácter fundamentalmente metalúrgico. En el siglo IX, el asentamiento se trasladó medio kilómetro al norte, perdurando hasta el siglo XIV d.C. Este segundo emplazamiento tuvo una vocación tanto metalúrgica como agrícola.
\end{abstract}

Son varios también los aspectos que, por su significación, destacan en la investigación llevada a cabo: a) Bagoeta nace en una fecha muy temprana (ca. 600 d.C.) como establecimiento ferrón capaz de abarcar el proceso productivo completo, desde la reducción del mineral hasta la forja final de los objetos de consumo. b) En torno al cambio de milenio la presencia de algunos indicadores (calles empedradas, movilización de recursos, introducción de nuevos modos constructivos, construcción de una iglesia, etc.), dan testimonio de un profundo cambio social que parece estar en la base de las transformaciones que documenta el registro arqueológico.

Palabras clave: asentamiento medieval; metalurgia del hierro; hornos de reducción; fraguas; agricultura; terrazas agrícolas.

\begin{abstract}
Given that the considerable volume of information generated by archaeological intervention in the settlement of Bagoeta is still under study, the conclusions presented here represent no more than a step forward that nonetheless allows us to confirm the existence of a settlement consisting of two distinct locations separated by a distance of 500 metres. The first was active between the 7th and 8th century A.D., exhibiting a markedly metallurgic character. In the 9th century, the settlement moved around 500 metres northwards, surviving until the 14 th century A.D.. This second location brought together both agricultural activity and ironmongery.
\end{abstract}

There are also a number of aspects arising from the investigation that stand out for the significance they hold: a) Bagoeta began life at a very early date (around 600 A.D.) as an iron settlement capable of encompassing the entire production process, from mineral reduction to the final forging of objects of consumption. b) The presence of various indicators such as cobbled streets, resource mobilisation, new construction methods, building of a church, etc. is evidence of a profound process of social change around the turn of the millennium that appears to be at the heart of the transformations documented in the archaeological record.

Key words: medieval settlement; iron metallurgy; slag-tapping furnace; forges; agriculture; agricultural terraces

\footnotetext{
* GPAC: Grupo de Investigación en Patrimonio Construido. Universidad del País Vasco. Centro de Investigación y Estudios Avanzados "Lucio Lascaray". Este trabajo de investigación ha sido realizado con fondos procedentes del PROGRAMA TCP (CSD2007-00058) -CONSOLIDER INGENIO 20 I 0, financiado por el Ministerio de Ciencia e Innovación y titulado "Programa de Investigación en Tecnologías para la valoración y Conservación del Patrimonio Cultural CSD-TCP".

*** QARK, S.L
} 
El lugar de Bagoeta ' es hoy un despoblado situado en las inmediaciones del núcleo alavés de Luko, perteneciente al municipio de ArrazuaUbarrundia. Entre los años 2008 y 2009 fue objeto de una intervención arqueológica que afectó a más de $110.000 \mathrm{~m}^{2}$ de superficie, estableciéndose un programa de trabajo que incluyó la prospección intensiva, el control del desbroce superficial, la realización de sondeos valorativos y finalmente la excavación en extensión de una parte del yacimiento. Las investigaciones, aun en proceso, están permitiendo conocer la configuración espacial de este lugar, aunque dada la complejidad y provisionalidad de los resultados debemos ser prudentes en su interpretación. Así lo expresábamos en un primer avance efectuado recientemente (AZKARATE, MARTÍNEZ, RODRIGUEZ, SOLAUN, 2010) y que sirve como base de esta nueva aproximación, en la que, además de repetir algunas de las evidencias mostradas en aquella ocasión, presentamos otras más recientes, fruto de las investigaciones efectuadas en los últimos meses. Con todo, y tal y como se apuntaba en el avance mencionado, podemos confirmar que los restos de ocupación humana se dispusieron en dos sectores bien diferenciados, separados entre sí por unos 500 metros (Fig. I).

\section{EL SECTOR SUR (siglos VII-VIII d.C.)}

En él se ha documentado, con certeza, la ocupación más antigua de un asentamiento cuyos orígenes podemos retrotraer a principios del siglo VII d.C., perdurando hasta la centuria siguiente 2 . Aunque la excavación afectó a una amplia superficie (en torno a los $5.000 \mathrm{~m}^{2}$ ), los vestigios conservados de esta primera ocupación son muy reducidos, concentrándose en una superficie de apenas $350 \mathrm{~m}^{2}$.

La escasez de testimonios, en cualquier caso, no debe interpretarse necesariamente como una ocupación de escasa entidad y, menos aún, con una determinada categoría de asentamiento ${ }^{3}$. Es urgente evitar este tipo de reduccionismos interpretativos y tener en cuenta que las continuas roturaciones agrícolas efectuadas hasta época reciente causaron una fuerte alteración en el terreno, provocando una progresiva disminución en altura que pudo llegar, en algunos casos, a superar el metro de altura respecto a la cota original ${ }^{4}$.

La prospección superficial de las laderas vecinas del monte Roba a lo largo de 250 metros de lugar, ofreció además abundantes muestras de escoria residual lo que vendría a confirmar la mayor extensión del asentamiento, cubierto actualmente por la nueva autopista del Norte, AP-I. Ha de decirse en consecuencia que, en este caso como en otros muchos, lo que se documenta en el registro arqueológico puede no ser sino testimonio parcial de un conjunto mayor, hoy desaparecido.

En lo que se refiere a este primer sector se han reconocido al menos tres cubetas o pozos de almacenamiento y diferentes agujeros de poste pertenecientes a varias estructuras situadas a nivel de suelo, difíciles de caracterizar. La

\footnotetext{
I La primera referencia escrita a la aldea de Bagoeta data del año 952, momento en que aparece citada dentro de los bienes que Diego Beilaz entrega al Monasterio de San Millán. Posteriormente, en año 1025, se encuentra también recogido en "la Reja de San Millán" como pagador de una reja (UBIETO, 1976; GARCÍA DE CORTÁZAR, 1969).

2 Las dataciones radiocarbónicas efectuadas a la materia orgánica contenida en los rellenos de amortización de cuatro agujeros (UE

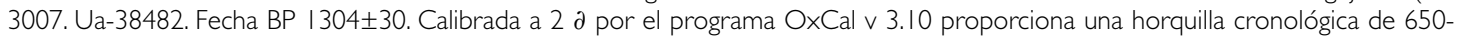
$780 \mathrm{AD}$ al 95,4\%; UE 3016. Ua-38483. Fecha BP I362 \pm 30 . Calibrada por el programa OxCal $\vee 3.10$ proporciona unas horquillas

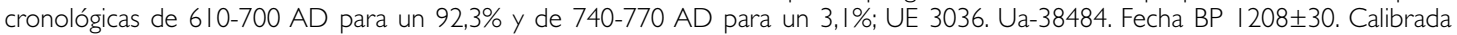
por el programa OxCal v 3.10 proporciona unas horquillas cronológicas de 690-750 AD para un 10,9\% y de 760-900 AD para un 84,5\%; UE 3039. Ua-38485. Fecha BP 1399 \pm 30 . Calibrada a $2 \sigma$ por el programa OxCal v 3.10 proporciona una horquilla cronológica de 590-675 AD al 95,4\%), complementada con la secuencia estratigráfica del yacimiento, ha permitido precisar esta horquilla cronológica.

3 En efecto, nos parece necesario advertir seriamente sobre los riesgos que conllevan las inferencias que, de modo precipitado, se derivan en ocasiones de los datos arqueológicos. Por ejemplo cuando de la mayor o menor entidad de los restos conservados se deduce la naturaleza de un lugar, clasificándolo en uno u otro tipo de asentamiento. Es el caso de determinados testimonios identificados -prematuramente en nuestra opinión- como granjas campesinas (QUIROS, 2009b: 389-39I) sin haber analizado suficientemente la influencia de las circunstancias postdeposicionales que, frecuentemente, trasforman radicalmente la naturaleza originaria del lugar.

4 Estimación basada en la sección conservada en los pozos de almacenamiento, de amplio diámetro de boca (superior a I,5 metros) y escasa profundidad (apenas medio metro de altura).
} 
presencia de estos agujeros de poste denuncia el carácter perecedero de su arquitectura, en línea con las técnicas constructivas bien conocidas en otros poblados alaveses altomedievales.

El hecho más significativo de este lugar es, sin embargo, la documentación de abundantes desechos productivos de hierro -escorias, carbones y revestimientos de arcilla rubefactadaformando parte de los rellenos que amortizaban estas estructuras ${ }^{5}$. El estudio metalográfico preliminar ${ }^{6}$ denuncia la presencia de escorias pertenecientes tanto a labores de reducción como de post-producción, certificando la existencia de un establecimiento metalúrgico del hierro capaz de abarcar la cadena operativa al completo: reducción, afinado y forja.

Se han reconocido, efectivamente, residuos relacionados con el proceso de reducción del mineral, principalmente escoria colada proveniente de hornos con salida de evacuación de los desechos (slag-tapping furnace). El cribado por imanes ${ }^{7}$ ha detectado, además, un volumen significativo de residuos magnéticos entre los que destacan microescorias derivadas del trabajo de forja con martillo (hammerscale): esferas y copos. Como se sabe, las spheres son resultado de la solidificación de pequeñas gotas de escoria líquida expulsadas del hierro durante el trabajo de forja en caliente, bien durante la transformación del metal bruto en barras, bien cuando dos componentes son soldados a martillo. Cuando las esferas no están frías y se martillea sobre el yunque, surgen las escorias aplanadas (copos o flakes) que pueden llegar, incluso, a desintegrarse (STARLEY, 1995).

El abastecimiento del mineral de hierro no debió ser mayor problema, dada la riqueza de evidencias mineras existente en el entorno. En el mapa de indicios que adjuntamos (Fig. 2), se recogen algunos de los yacimientos férricos diseminados desde la sierra de Elgea hasta las estribaciones del Gorbea. Se trata, generalmente, de pequeños afloramientos superficiales de óxidos de hierro (principalmente goethitas) ${ }^{8}$ procedentes de la estructura geológica del anticlinal de Bilbao, con una litología caracterizada por areniscas, lutitas y limolitas calcáreas del Cretácico Inferior. Aunque sus recursos ferruginosos pudieran parecernos actualmente muy limitados, hay que tener en cuenta que todos estos yacimientos poseían potencial suficiente como para ser explotados en una época en la que la rentabilidad derivaba no tanto de la cantidad de material existente cuanto de la facilidad de extracción del mineral y su alto contenido en hierro (ARGÜELLO, 1998). Prueba de ello es la amplia tradición ferrona atestiguada desde época bajomedieval en la cercana población de Legutiano (Villarreal de Álava), cuyo fuero (año I333) reserva para el rey las "minas de oro, o de plata, o de fierro, o de otro metal cualquiera", así como el derecho a autorizar la construcción de nuevas ferrerías. Además, la presencia de cantidades significativas de manganeso $(\mathrm{MnO})$ en las escorias analizadas (hasta un 6\%) iría en consonancia con los altos contenidos que muestra este elemento en la goethita, confirmando el origen del metal utilizado.

Tan importante como el mineral era el agua -asegurada por el río Bagueta, situado unos 500 metros al oeste del yacimiento- y el carbón vegetal, producido mediante el sistema tradicional de carboneras. Estas labores exigían, obviamente, una amplia masa boscosa en las cercanías de la instalación ferrona, de la que nos dan testimonio el propio topónimo "Bagoeta" -hayedo en lengua vasca- y los análisis palinoló-

5 Como apuntan Mannoni y Giannichedda (2006: 212), los desechos productivos suelen reencontrarse generalmente en estratos extraños a los del contexto primario de proveniencia, pero casi siempre cerca del lugar de producción.

6 El estudio SEM-EDS de las escorias pirometalúrgicas recuperadas en el yacimiento de Bagoeta se encuentra en proceso de ejecución por parte de Marc Gener (IH/CCHS-CSIC).

7 Se trata de una técnica efectuada con potentes imanes que atraen las partículas magnéticas presentes en la muestra de tierra seleccionada, previamente desecada. Con posterioridad se pesan, seleccionan e identifican los diferentes residuos, dentro de las limitaciones que supone un examen macroscópico como este (STARLEY, 1995; McDONNELL, STARLEY, 2002).

8 Sólo en aquellos yacimientos de mayor importancia, como es el caso de Mina Miñagañe ( $\left.n^{\circ} 2\right)$, se registran galerías, explotadas a finales del siglo $X I X$ y principios del siglo $X X$. 
gicos $^{9}$. Sin embargo, el estudio antracológico ${ }^{10}$ efectuado a los restos de madera carbonizada recogidos en los diferentes depósitos de este sector indica un predominio absoluto de Quercus subgénero Quercus (roble albar, pedunculado, pubescente, quejigo, melojo), lo que refleja la preferencia como combustible del roble, una madera de excelente calidad por sus altas propiedades caloríficas. De estos resultados puede deducirse, también, la existencia de una explotación muy selectiva de la madera utilizada como combustible, un signo más, sin duda, de la especialización que alcanzaba la actividad metalúrgica en Bagoeta.

Los mismos estudios arqueobotánicos denuncian además la ausencia de polen de cereal (cerealia) en todas las muestras analizadas, lo que permite pensar que los campos de cultivo, de existir, estuvieron relativamente alejados (LÓPEZ SÁEZ, LÓPEZ GARCÍA, BURJACHS, 2003 y LÓPEZ SÁEZ, LÓPEZ MERINO, 2005) y, por consiguiente, que el emplazamiento de esta primera ocupación estuvo condicionado más por su proximidad a las venas de hierro y su vocación decididamente metalúrgica.

\section{EL SECTOR NORTE (siglos IX-XIV d.C.)}

En el siglo IX el asentamiento humano se trasladará unos 500 metros al norte. La intervención arqueológica ha permitido exhumar algo más de una hectárea correspondiente sólo al núcleo central de este nuevo emplazamiento, ya que el resto se extendía hacia el sureste y el noroeste del sector excavado, ocupando una superficie superior a las 3 hectáreas de terreno (Fig. 3A).

Son varios los rasgos que nos parecen especialmente relevantes en este lugar (Fig. 3B): I) La existencia de una calle parcialmente empedrada que, actuando como eje vertebrador del nuevo urbanismo en dirección noroestesureste, articuló el lugar durante los 500 años que transcurrieron hasta su abandono. En su margen septentrional, una atarjea construida con lajas calizas recogía las aguas provenientes de la ladera, conduciéndolas hacia las zonas bajas del río Bagueta. 2) La presencia, a uno y otro lado del eje citado, de diferentes unidades domésticas separadas entre sí por cercados de madera, de las que la intervención arqueológica ha podido documentar tres. 3) La construcción, al noroeste, de la iglesia de Santa Marina, hoy testigo en ruinas del primitivo templo de Bagoeta.

Poderes con capacidad organizativa, urbanismo, calles empedradas, propiedades productivas bien delimitadas, templo cristiano... en definitiva, una suma de elementos de gran significado socio-económico y político que vuelven a presentarse en forma y tiempo similar a otros lugares bien conocidos de la Llanada alavesa.

\section{Historia de una de las unidades domésticas excavadas}

A pesar del carácter provisional de este avance, es posible caracterizar con seguridad una de las tres unidades domésticas que hemos visto organizadas a izquierda y derecha de la calle central. Aunque sus límites se extienden fuera del área que pudo excavarse, todo apunta a un solar rectangular de extensión superior a los $2.500 \mathrm{~m}^{2}$ y límites bien definidos: por el oeste con el eje urbano recién mencionado y por el norte por un cercado sobre zanjas y postes que lo separaba de la unidad doméstica vecina. Son varias las fases que cabe distinguir en su historia secular.

\section{I.I. PRIMERA FASE (Siglos IX-X)}

Es la más difusa de todas y con un registro arqueológico más débil. Aún así ha podido documentarse una gran concentración de agujeros de poste abiertos en la zona sureste del recinto, en posición ligeramente dominante. Estos testimonios responden sin duda a las estructuras constructivas que conformaban

\footnotetext{
9 Que evidencian un importante bosque de pinos (especie oportunista que crece después de aclareos o talas de especies del género Quercus), junto al que se situaban diferentes espacios abiertos destinados a pastos (análisis preliminar efectuado por José Antonio López y Sebastián Pérez).

I0 A cargo de Mónica Ruiz y Lydia Zapata, de quien proceden los datos que aquí se presentan.
} 
el área habitacional y/o artesanal, todas ellas levantadas con técnicas perecederas. Aunque resulta muy complicado caracterizar y datar estas viejas estructuras, el material cerámico contenido en los rellenos de algunos agujeros y pozos de almacenamiento permite fijar la fecha final de uso entre los siglos X y XI d.C. (Fig. 3C).

\section{I.2. SEGUNDA FASE (Siglos XI-XIII)}

A fines del siglo $X$ o inicios del siglo $X I$ se produce una notable modificación en la reorganización del espacio doméstico y productivo descrito. El rasgo más destacado es el traslado del área residencial hacia espacios ocupados por antiguas parcelas sin edificar (eras, campos de cultivo...), al tiempo que los antiguos espacios construidos son reconvertidos en espacios agrarios. Comportamientos de este tipo son detectados también en el resto de unidades domésticas excavadas, siguiendo pautas de desplazamiento análogas, desde las zonas más prominentes hacia las zonas más bajas de la vaguada, junto al camino.

Aunque las nuevas estructuras construidas se ajustan básicamente al parcelario original, evidenciando la estabilidad de la unidad doméstica, los límites se hacen menos estrictos al suprimirse algunos marcadores como el cercado que cerraba la unidad por el norte. El resultado de esta reorganización espacial es un nuevo modelo de unidad productiva constituido por tres áreas funcionalmente distintas: una residencial emplazada en el centro de la parcela, otra agrícola situada a ambos lados del espacio habitacional y una última de carácter industrial localizada en un extremo (Fig. 3D).

\section{I.2.I. El área residencial (Fig. 5)}

En el área central de la unidad doméstica se sitúa la vivienda, organizada según el modelo de casa unitaria ya registrado en Gasteiz y bien conocido en otros contextos europeos (AZKA-
RATE, SOLAUN, 2009 y GALETTI, 200I). Se compone ésta de un único edificio de planta rectangular ( 16 metros de longitud por 6 metros de anchura), paredes de mampostería caliza trabada con un mortero arenoso bastante deleznable y compartimentación interior. Aunque el arrasamiento sufrido ha impedido la conservación de estos muros por encima del medio metro de altura, su grosor (0,6 metros) y la ausencia de agujeros de poste en el trazado invita a pensar en paredes de piedra para la planta baja, sobre las que apoyarían entramados de madera o alzados de barro amasado.

El interior se hallaba ligeramente rebajado respecto a la cota exterior, hasta llegar a un estrato de roca compacta. Son precisamente estos rebajes en el terreno los que permitieron precisar la morfología completa del edificio y certificar la existencia de un muro medianil que dividía inicialmente el edificio en dos estancias contiguas. La más meridional, de aproximadamente $16 \mathrm{~m}^{2}$ de superficie, debió contar con un suelo de madera, destruido por un posterior incendio, a juzgar por las huellas registradas arqueológicamente. Este entarimado estuvo destinado, muy posiblemente, a proteger el cereal de la humedad del terreno, lo que permite interpretar la estancia como un lugar de almacenamiento y/o secado de la reserva agrícola.

La segunda estancia -contigua al norte- triplicaba en extensión a la ya descrita. De ella ha podido reconocerse un suelo arcilloso de coloración oscura y, en su extremo noreste, un hogar cuadrangular de cuidada factura con aproximadamente un metro de lado. Presentaba una base de lajas calizas sobre las que se extendía una capa de arcilla rubificada y compactada por efecto del fuego. Un resalte perimetral de piedra aislaba el hogar del suelo circundante. Las analíticas efectuadas al material recuperado en esta estancia " la identifican con un espacio doméstico dotado de una

\footnotetext{
I I Los exiguos porcentajes de escoria recuperados en el suelo mediante el sistema de cribado magnético (packin factor: 0,000 I. El packin factor es un valor entre 0 y I relativo a la proporción de escoria por volumen) descartan su uso como fragua (como ocurrirá posteriormente, tras la ampliación de la casa), debiendo pensar en un espacio doméstico. Es más, el residuo resultante de la muestra analizada está dominado por materiales de origen no magnético, destacando la abundante presencia de semillas sin carbonizar.
} 
cocina y varios ámbitos de uso habitacional, separados quizás por pequeños tabiques de tablazón y/o ramas entrelazadas revestidas con arcilla (clayonnage), de los que la excavación ha recuperado fragmentos puntuales.

La cerámica recuperada en el suelo de esta última estancia (segunda mitad del siglo XII) nos llevó a fechar en esta centuria la construcción de la vivienda (AZKARATE, MARTíNEZ, RODRIGUEZ, SOLAUN, 2010). Hoy hemos de corregir, sin embargo, aquella primera valoración, gracias a criterios estratigráficos que no se valoraron suficientemente en su momento. Sabemos (como veremos a continuación) que las terrazas fueron construidas en el siglo XI. El hecho de que se dispongan alrededor de la casa, subordinados a ella, e incluso adosadas a su fábrica como en el caso de una de ellas, evidencia que la vivienda se construyó de manera coetánea o anterior a los campos ${ }^{12}$. En otras palabras, a finales del siglo $\mathrm{X}$ o el siglo $\mathrm{Xl}$.

Esta casa tuvo otros edificios auxiliares de menor entidad situados en sus inmediaciones, repitiendo un modelo bien registrado en nuestras excavaciones en Álava. Se trata de dos estructuras semiexcavadas en la roca sobre las que, en la fase siguiente, se emplazará la ampliación de la casa. La primera de ellas, de planta cuadrangular, se situaba inmediatamente al norte y ocupaba una superficie de $6 \mathrm{~m}^{2}$, mientras que la segunda, ubicada al noroeste, tuvo planta ovalada. Ambas serán amortizadas con las reformas efectuadas en la segunda mitad del siglo XII y que veremos en el capítulo siguiente.

\section{I.2.2. Los espacios agrícolas (Fig. 5)}

Flanqueando el edificio residencial, a norte y sur del mismo, se situaron sendos espacios agrícolas de uso intensivo destinados a huertas y campos de cultivo, que se extendían fuera incluso de los términos de la excavación.

El espacio septentrional estuvo conformado por un sistema de tres terrazas escalonadas (superior, media e inferior) de más de 14 metros de anchura y entre 9-15 metros de fondo que ocupaban una superficie aproximada de $450 \mathrm{~m}^{2}$ En su construcción se utilizó un único aporte de tierra orgánica, previa construcción de sendos muretes de contención en sus frentes, con desmonte de la ladera ${ }^{13}$. Inmediatamente debajo del horizonte mineral orgánico y detrás de los muros de las terrazas se depositó una cama de preparación compuesta por piedra y grava destinada a asegurar el drenaje de las terrazas y evitar así la acumulación de agua y sedimentos. Se trata, por tanto, de un sistema de aterrazamiento construido de una sola vez que corrige la pendiente de la ladera arrasando completamente el paleosuelo vegetal hasta el nivel natural. Su construcción, a juzgar por la cerámica recogida en los aportes de tierra, puede situarse en el siglo $\mathrm{XI}^{14}$.

El área meridional fue producto también de un proceso de desmonte de la ladera con relleno sistemático. El espacio se caracteriza por presentar una primera terraza inferior delimitada por un muro de contención curvo que se adapta a las curvas de nivel del terreno. Adosado a este muro se registra un relleno inferior de drenaje con gran cantidad de piedra, sobre el que se depositaba el nivel orgánico. Aunque este último nivel apenas conservaba 60 $\mathrm{m}^{2}$ de superficie, la ausencia de otros restos de ocupación en la zona permite suponer que la terraza se extendía varios metros al sur y este, conectando dos nuevos bancales escalonados (medio y superior) hasta completar, entre todos, una superficie mínima de $400 \mathrm{~m}^{2}$. El

\footnotetext{
12 El ejemplo más evidente de posterioridad de estos espacios respecto a la casa es la terraza inferior situada al suroeste, que se adosa a ella.

13 Atendiendo a la clasificación realizada por el LAr nos encontraríamos ante un sistema de desmonte de ladera con relleno sistemático depositado de una sola vez (BALLESTEROS, CRIADO, ANDRADE, 2006).

I4 UE 5 I53 (relleno terraza media). Grupo V: I individuo (33\%) y Grupo Vl: 2 individuos (66\%). Cotejado con los conjuntos cerámicos presentados en SOLAUN (2005) ofrece una cronología situada entre el siglo XI y la I a mitad del siglo XIl; UE 4093 (relleno terraza superior). Grupo V: I individuo (17\%) y Grupo VI: 5 individuos (83\%). Cotejado con los conjuntos cerámicos presentados en SOLAUN (2005) ofrece una cronología centrada entre el siglo XI.
} 
bancal superior aún mantenía restos del muro de contención frontal, de trazado muy sinuoso. Su contemporaneidad con la anterior serie de terrazas parece estar fuera de dudas, ya que la cerámica recogida apunta también al siglo XI ${ }^{15}$.

Los resultados de los análisis físico-químicos efectuados a los suelos de estos bancales han proporcionado elementos que los vinculan con seguridad con campos de cultivo y/o huertas. Una primera lectura de estos análisis ofrece unos elevados niveles de fósforo y materia orgánica, que resultan más significativos si se analizan junto a otra serie de elementos como la relación carbono/nitrógeno, por lo que todo apunta a que fueron abonados para su cultivo ${ }^{16}$.

Del mismo modo, el estudio arqueobotánico preliminar efectuado sobre las muestras recogidas en las terrazas del espacio septentrional ha identificado semillas y pólenes de cereal en porcentajes suficientes como para confirmar el desarrollo de cultivos in situ. Los primeros resultados del estudio carpológi$\mathrm{CO}^{17}$ corroboran asimismo la presencia de, al menos, cuatro especies domésticas: dos cereales (trigo desnudo y cebada de 6 carreras) y dos leguminosas (yeros y habas). El resto de las especies identificadas pertenecen a la categoría de plantas silvestres, entre las que destacan la Asperula o Lolium que forman parte del cortejo de malas hierbas que acompañan a los cereales en los campos.

No se documentan, sin embargo, áreas extensas de almacenamiento como las registradas en Gasteiz (AZKARATE, SOLAUN, 2009: 422-423) -salvo un silo ubicado en la terraza inferior- por lo que todo apunta a un espacio agrícola destinado básicamente a cubrir las necesidades de la unidad familiar.

\section{I.2.3. La instalación metalúrgica (Fig. 5)}

En el extremo noroeste de la unidad que venimos describiendo, la intervención arqueológica pudo documentar los restos de una fragua y de un horno de fundición de hierro que testimonian la existencia de un establecimiento siderometalúrgico capaz de desarrollar el proceso productivo completo, desde la reducción del mineral hasta la forja de de los productos finales.

- La fragua. Fue construida en el siglo XI ${ }^{18}$ amortizando el viejo vallado que separaba la unidad doméstica central de la situada más al norte. Se trata, en este caso, de un gran edificio de planta rectangular (12 metros de longitud por 7,5 metros de anchura) levantado con técnicas constructivas similares a las descritas en la casa unitaria. Se han podido documentar, en efecto, paredes de mampostería caliza de 0,8 metros de grosor reforzadas en los esquinales por piezas regularizadas de mayor tamaño que, aunque sólo conservaban cuatro hiladas en altura, debieron componer toda la planta baja. La solidez constructiva de esta fábrica y la presencia de un apoyo de piedra emplazado en el costado occidental, confirman la existencia de un piso superior levantado con materiales más livianos y destinado muy posiblemente a lugar de almacenamiento.

Su primer suelo se construyó con arcilla y cantos rodados, garantizando de esta forma el drenaje de unas aguas de escorrentía que, recogidas por el canal registrado al exterior de su fachada occidental, acababan en la atarjea situada en el camino principal. En el extremo sudoriental de la estancia se emplazó el fuego bajo de la fragua, de planta circular, compuesto por una capa de arcilla rubificada sobre una base de escorias de

\footnotetext{
I 5 UE 4094 (relleno terraza). Grupo V: I individuo (33\%) y Grupo VI: 2 individuos (66\%). Cotejado con los conjuntos cerámicos presentados en SOLAUN (2005) ofrece una cronología situada entre el siglo XI y la la mitad del siglo XII.

16 Datos procedentes del estudio que está realizando María Ruiz del Arbol.

17 A cargo de Leonor Peña-Chocarro y Lydia Zapata, de quien proceden los datos recogidos en este trabajo.

18 Cronología estimada atendiendo a las relaciones estratigráficas de posterioridad de la fragua respecto al vallado y al material cerámico recuperado en el relleno de amortización de la zanja que integraba este cercado. UE 48I5 (relleno amortización zanja). Grupo I: I individuo (20\%), Grupo V: I individuo (20\%) y Grupo VI: 3 individuos (60\%). Cotejado con los conjuntos cerámicos presentados en SOLAUN (2005) ofrece una cronología situada entre la segunda mitad del siglo X y todo el siglo Xl.
} 
hierro y protegido por un resalte perimetral de piedra. Otras forjas, como las documentadas en Gasteiz (AZKARATE, SOLAUN, 2007 y 2009; PLATA, SAIZ, BENEDET, 20I0), dan buena prueba del predominio de este tipo de hogares bajos durante toda la Edad Media -en los que el herrero trabajaba de rodillassin que se haya documentado, de momento, la introducción de hogares sobreelevados.

Una reforma en el edificio a finales del siglo XIII ${ }^{19}$ y que afectó al extremo oriental del mismo, sustituyó el primitivo suelo por una nueva superficie de uso compuesta por varias bolsadas de tierra negruzca (algunas de ellas procedentes posiblemente del antiguo suelo) que contenían numerosos desechos productivos (carbones y escoria) derivados de las labores de forja 20.

- El horno de fundición de hierro. En las inmediaciones de la fragua por su lado septentrional, se emplazó uno de los hornos de fundición que componían la instalación metalúrgica. Se trata de un horno en columna con salida de evacuación de las escorias (slag-tapping furnace) de amplia difusión en Europa occidental (TYLECOTE, 1987) y que constaba de dos estructuras: la cubeta de reducción y la fosa de colada. En este caso pudo documentarse la cubeta de planta cuadrangular (0,90 metros de lado) con su fondo ligeramente excavado en el terreno y revestido por un manteado de arcilla rubefactada (Fig. 6). La aparición de revestimientos de arcilla con improntas vegetales en los niveles de amortización del horno parece denunciar la existencia de chimeneas superiores construidas mediante una técnica similar al clayonnage. La ausencia, sin embargo, de fragmentos de tuberías cerámicas de ventilación -como las localizadas en algunas estructuras altomedievales del norte europeo (LEROY, MERLUZZO, 1988)- invita a pensar en un sistema compuesto por simples aberturas en la pared que asegurasen el tiro suficiente para la reducción. Una pequeña lengua de arcilla rebosando el lateral oeste de la cubeta testimonia el orificio de evacuación de las escorias. Lamentablemente, la fuerte alteración del terreno ha provocado la práctica desaparición de la fosa de colada, destinada a recoger los desechos productivos.

Aunque la ausencia de contextos coetáneos a su uso impide conocer la fecha concreta de su construcción, sí podemos establecer el momento de abandono a través del material cerámico recuperado en sus rellenos de amortización. La cronología estimada apunta al siglo $\left.X\right|^{21}$, por lo que puede deducirse que fragua y horno coexistieron en el tiempo. La estructura dendrítica de la wüstita presente en las escorias analizadas nos proporciona además información de la tecnología pirometalúrgica de los hornos utilizados, en los que se alcanzaban con regularidad temperaturas superiores a $1300^{\circ} \mathrm{C}$, una circunstancia que se ajusta perfectamente a la tecnología de los slag-tapping furnace.

\subsubsection{Las reformas de la segunda mitad del siglo XII (Fig. 8)}

En la segunda mitad del siglo XII o inicios de la centuria siguiente ${ }^{22}$ el edificio residencial se

19 Cronología estimada atendiendo a una moneda de vellón de Sancho IV (I284-1295) y al material cerámico recuperado en el suelo de la fragua. UE 4800 (suelo fragua). Grupo I: I individuo (residual), Grupo V: 10 individuos (58\%), Grupo VI: \pm 5 individuos (29\%) y Grupo X: 2 individuos (I3\%). El Grupo VI atesora, no obstante, numeroso material residual, por lo que el número de individuos asignado puede presentar algunas desviaciones a la baja. Cotejado con los conjuntos cerámicos presentados en SOLAUN (2005) y SOLAUN, ESCRIBANO (2006) ofrece una cronología situada entre la segunda mitad del siglo XIII y la primera mitad del siglo Y XIV.

$20 \mathrm{El}$ cribado por imanes de este suelo ha detectado fundamentalmente microescorias en forma de esferas procedentes del trabajo de forja en caliente.

2 I UE 458 I (relleno amortización horno). Grupo I: I individuo (33\%) y Grupo VI: 2 individuos (66\%). Cotejado con los conjuntos cerámicos presentados en SOLAUN (2005) ofrece una cronología situada entre la segunda mitad del siglo X y todo el siglo XI.

22 Cronología estimada atendiendo a la secuencia estratigráfica y al material cerámico recuperado en los suelos de las nuevas estancias construidas.

UE 5 I58 (suelo estancia 3). Grupo V: 4 individuos (50\%) y Grupo VI: \pm 4 individuos (50\%). Este último grupo atesora, no obstante, numeroso material residual, por lo que el número de individuos asignado puede presentar algunas desviaciones a la baja. Cotejado 
ampliará con un nuevo cuerpo rectangular de 15,5 metros de longitud por más de 6 metros de anchura que, adosado perpendicularmente a su extremo septentrional, generará una planta en forma de $L$ de aproximadamente $330 \mathrm{~m}^{2}$ y un amplio patio delantero, similar a los que conocemos en Vitoria-Gasteiz. Con su construcción, se suman al edificio dos nuevas estancias destinadas también -y esto es especialmente significativo- a usos metalúrgicos. Este hecho, en cualquier caso, no provocó el abandono de la actividad agrícola puesto que se mantuvieron en uso las terrazas que se han visto en páginas precedentes. La reforma fue consecuencia, muy probablemente, de un incendio que acaeció por estas fechas y cuyos efectos recogíamos al describir una de las estancias del edificio descrito en un capítulo anterior (1.2.1).

Una de estas nuevas estancias, de aproximadamente $35 \mathrm{~m}^{2}$ de superficie y adosada por el norte al primitivo edificio, fue una fragua. En su interior se documentaron restos de un suelo cuyo cribado por imanes aportó significativos porcentajes de escoria proveniente de las labores de forja (hammerscale), además de una importante cantidad de polvo metálico y otros desechos productivos difíciles de identificar ${ }^{23}$. Lo más destacable de esta instalación era, sin embargo, la presencia de un total de cinco hogares situados a ras de suelo en el extremo meridional de la habitación, tres de los cuales pudieron funcionar de manera simultánea. Algunos de ellos mantenían casi intacta su morfología original, muy similar al descrito más arriba, mientras que de otros apenas resta una mancha de arcilla rubefactada.
En la superficie del suelo se recuperó además una gran cantidad de elementos metálicos, entre los que destacaríamos un cuchillo y una punta de lanza. Todos estos indicios materiales, junto a la presencia de varios fragmentos de piedras de afilar en los espacios adyacentes, son argumentos suficientes para situar en esta estancia una fragua o herrería especializada en la fabricación de armas. Una producción que también se documenta en la vieja fragua del noroeste donde se recuperaron tres puntas de dardo para ballesta $y$, en general, en el resto de unidades productivas de Bagoeta en las que cuchillos, espadas cortas y objetos metálicos diversos aparecen por doquier.

La segunda de las nuevas estancias se adosaba por el oeste a la fragua descrita, ocupando una superficie de $43 \mathrm{~m}^{2}$. Presentaba un suelo de tierra batida muy negro con abundantes carbones y carecía de hogar, lo que hace pensar en su uso como carbonera y/o almacén asociado al taller metalúrgico. Una función similar parece que acogió la vieja estancia después del incendio que asoló la casa. Las marcas de fuego en los alzados de sus muros y el registro de un estrato negruzco con abundantes restos de tablazón quemado dan fe de este suceso que provocó, a su vez, cambios importantes en la estancia. El antiguo suelo de madera será sustituido por un piso de tierra batida, carente de hogar, donde, entre otros materiales, se documentó una piedra de afilar de disco. La aparición de teja en los suelos y niveles de amortización del edificio dan testimonio de la utilización de este material cerámico en la techumbre en los últimos momentos de ocupación.

con los conjuntos cerámicos presentados en SOLAUN (2005) ofrece una cronología situada entre la segunda mitad del siglo XII y la primera mitad del siglo XIII.

UE 5 I70 (suelo estancia 4). Grupo V: 10 individuos (45,5\%); Grupo VI: \pm I 0 individuos (45,5\%); Grupo X: I individuo (4,5\%) y Grupo XVIII: I individuo (4,5\%). El Grupo VI atesora, no obstante, numeroso material residual, por lo que el número de individuos asignado puede presentar algunas desviaciones a la baja. Cotejado con los conjuntos cerámicos presentados en SOLAUN (2005) ofrece una cronología situada entre la segunda mitad del siglo XII y la primera mitad del siglo XIII.

23 La intención de este cribado magnético fue la de recuperar y reconocer los diferentes desechos productivos generados en la forja, de cara a reconstruir todo el proceso de trabajo, labor que aún se encuentra en proceso. Como avance, se ha efectuado un cálculo aproximado de la cantidad total de escoria en el suelo con el objeto de obtener una estimación de la actividad metalúrgica. Para ello nos basamos en una sencilla fórmula enunciada por G. McDONNELL y D. STARLEY (2002) consistente en multiplicar el volumen del contexto $\left(0,7 \mathrm{I} \mathrm{m}^{3}\right)$ por un factor entre 0 y I relativo a la proporción de escoria por volumen (packin factor: 0,043) por la densidad de la escoria $\left(1,55 \mathrm{gr} / \mathrm{cm}^{3}\right.$ ), lo que nos da un peso total de 47,32 kilogramos. Como señalan estos mismos autores, la cantidad de escoria puede variar enormemente dependiendo de la naturaleza de la actividad y del área excavada. En nuestro caso, la cifra resultante debe tomarse como un primer valor de la actividad desarrollada en una forja rural alavesa del siglo XIII y, como tal, puede servir de referencia de cara a futuros análisis comparativos con otras instalaciones. 
La nueva instalación metalúrgica se completaba probablemente con nuevos hornos de reducción. La intervención arqueológica detectó uno de ellos, situado escasamente 10 metros al este de la casa y justo en el límite de la excavación, por lo que cabe imaginar que existieran estructuras de combustión similares fuera de la zona intervenida. A pesar de su deficiente estado de conservación, derivado del intenso arrasamiento en el terreno y del propio desmantelamiento de la estructura, todo indica que se trata de un nuevo horno en columna con salida de evacuación de las escorias, similar al descrito anteriormente.

El horno se encontraba amortizado por varios rellenos de tierra negruzca con gran cantidad de cenizas, carbones y revestimientos de arcilla que permiten datar su abandono en la segunda mitad del siglo XII ${ }^{24}$, coincidiendo con la fase inicial de la nueva forja. De su proximidad espacial con ésta cabe deducir que pudiera tratarse del primero de los hornos que, cumplida su función, fue sustituido por otros que debieron existir en sus inmediaciones, en un espacio que ha quedado fuera de la intervención arqueológica.

\section{I.3. FASE DE ABANDONO}

El abandono de la unidad doméstica -y por extensión, de toda la aldea de Bagoeta- se produce en el siglo XIV ${ }^{25}$, muy posiblemente a lo largo de la segunda mitad de esta centuria, según un proceso de despoblación-ruinadesaparición. Así se desprende de los niveles de destrucción registrados en los principales edificios, caracterizados por la abundante presencia de piedra, barro y teja proveniente de la ruina prolongada de sus alzados, entremezclados con otros materiales pertenecientes a la carpintería metálica, el ajuar doméstico o los desechos productivos de las instalaciones metalúrgicas.

La presencia, además, de otros aportes de tierra -en ocasiones cubriendo los anteriores niveles de abandono- destinados a amortizar los edificios permite suponer que, ya para el siglo XIV, se inicia un proceso de conversión del antiguo asentamiento en pastos o campos de cultivo de uso extensivo. Un litigio sobre pastos entre vecinos de Luko y Ullibarri-Gamboa a principios del siglo XVI nos informa además que la aldea ya se encontraba desaparecida para esta centuria, manteniéndose únicamente en pie la ermita de Santa Marina y un camino que comunicaba este templo con la cercana población de Ullibarri Gamboa, quizás el mismo eje viario que vertebraba el antiguo asentamiento medieval.

\section{DISCUSIÓN}

La gran mayoría de las instalaciones siderúrgicas del hierro que debieron existir en el País Vasco durante época alto y plenomedieval se habrían localizado en espacios de montaña, aprovechando su cercanía a las materias primas necesarias (carbón vegetal y mineral), a los cursos de agua y a los vientos dominantes. Esta es la principal idea que cabe deducir de la revisión bibliográfica realizada al respecto ${ }^{26}$. Yacimientos como los de Oiola IV en Trapagaran (LARRAZABAL, 1997; PEREDA, 1994 y 1997), Ilso Betaio en Artzentariz-Sopuerta (GORROCHATEGUI, YARRITU, 1984) o el más reciente de Callejaverde en Muskiz (FERNÁNDEZ CARVAJAL, 2008 y 2009), todos ellos con dataciones comprendidas entre los siglos X y XIII, corroborarían en efecto la

\footnotetext{
24 Cronología estimada atendiendo al material cerámico recuperado en los rellenos de amortización del horno:

UE 4I77. Grupo V: 2 individuos (40\%) y Grupo Vl: 3 individuos (60\%). Cotejado con los conjuntos cerámicos presentados en SOLAUN (2005) ofrece una cronología situada en la segunda mitad del siglo XII.

UE 4|47. Grupo V: I individuo (50\%) y Grupo VI: I individuo (50\%). Cotejado con los conjuntos cerámicos presentados en SOLAUN (2005) ofrece una cronología situada en la segunda mitad del siglo XII y las primeras décadas del siglo XIII.

25 Cronología estimada atendiendo a la secuencia estratigráfica y al material cerámico recuperado en los rellenos de amortización de la fragua y el edificio residencial. UE 4730 (relleno amortización fragua). Grupo V: 4 individuos (66\%); Grupo VI: I individuos (I 65\%); Grupo X: I individuo (16\%). Cotejado con los conjuntos cerámicos presentados en SOLAUN, ESCRIBANO (2006) ofrece una cronología situada en el siglo XIV.

$26 \mathrm{Al}$ menos para territorio vizcaíno y guipuzcoano (GORROCHATEGUI, J. el alii, I995; ETXEZARRAGA, I., 2004).
} 
existencia de una paleometalurgia vasca basada en las ferrerías de monte, o lo que es lo mismo, en talleres situados sobre collados o rellanos a media ladera, provistos de uno o más hornos de reducción en columna. Son las denominadas haizeolak ${ }^{27}$, nombre que en lengua vasca designa a las ferrerías de viento, en contraposición a las zeharrolak o ferrerías hidraúlicas.

A juzgar por los recientes descubrimientos, sin embargo, parece más bien que dicha impresión no es sino resultado del propio estado de la investigación arqueológica que, tradicionalmente, venía priorizando prospecciones e intervenciones muy puntuales en las zonas montañosas de Vizcaya y Guipúzcoa. Nada se sabía de Álava salvo, paradójicamente, que tenía una importante actividad metalúrgica a juzgar por las informaciones textuales. Es de todos sabido que la archiconocida "Reja de San Millán" (año 1025) recogía el listado de las casi 300 aldeas a las que el monasterio de San Millán exigía el pago de censos en hierro ${ }^{28}$, una obligación que se mantuvo un siglo más tarde en los Ilamados "Falsos votos de San Millán", pero que no se extendió a los territorios vizcaíno y guipuzcoano. Siempre sorprendió a algunos autores que las fuentes escritas señalasen a las tierras llanas de Álava nuclear como los lugares con mayor actividad metalúrgica en los primeros siglos medievales.

Esta aparente contradicción entre fuentes arqueológicas y textos escritos ha comenzada a disiparse con la aplicación sistemática de nuevas estrategias de excavación en open area, con resultados que confirman la importancia que alcanzó la actividad siderometalúrgica en los asentamientos de la Llanada alavesa desde fechas muy tempranas. En realidad, Bagoeta no hace sino reafirmar, a una escala mucho mayor, algo que ya habíamos constatado en la cercana Gasteiz. (AZKARATE, SOLAUN, 2009). Es, por tanto, un lugar clave puesto que aporta información relevante sobre la presencia muy madrugadora de lugares exclusivamente dedicados a la actividad metalúrgica.

27 También agorrolak (= ferrerías en seco)

28 Reja de San Millán. Año 1025 (Ubieto, 1976).
Bagoeta nace, en efecto, en torno al año 600 d.C. con instalaciones capaces de abarcar el proceso productivo completo, desde la reducción del mineral hasta la forja final de los objetos de consumo. Los testimonios conservados en el registro arqueológico, pertenecientes a este momento fundacional, no son abundantes (cfr. supra) y podrían conducir a algunos arqueólogos a interpretarlos como una granja, basándose en criterios dimensionales, especialmente si preceden en el tiempo a otro lugar de hábitat mucho más estable que sí cabe calificarse como aldea.

No es desde luego nuestro caso y preferiremos referirnos a este lugar como un asentamiento del siglo VII d.C. que funciona como centro de producción especializado en manufacturas de tipo metalúrgico. No podemos evitar la mención de otros datos que nos parecen significativos: a) El asentamiento de Bagoeta está a muy pocos kilómetros de la necrópolis de Aldaieta; b) Ambos, asentamiento metalúrgico y necrópolis, coincidieron en el tiempo al menos en un siglo; c) Si algo caracteriza a los ajuares y depósitos procedentes de los contextos funerarios exhumados en Aldaieta es la abundantísima e inusual presencia de objetos de hierro. Y aunque no sea este el lugar para deducir conclusiones al respecto, sí lo es para recordar que es mucho lo que nos queda por saber sobre este periodo y que nunca resulta ocioso llamar a la cautela en el estado actual de nuestros conocimientos.

En el siglo IX, el asentamiento se desplazará unos 500 metros al norte, siguiendo un patrón de comportamiento bien conocido y descrito en otros contextos peninsulares y europeos (HAMEROW, 2002; PEYTREMANN, 2003; VIGIL-ESCALERA, 2007; QUIROS CASTILLO, 2009b). El nuevo emplazamiento (estable hasta el abandono definitivo de la aldea medio milenio más tarde) se organiza en torno a un eje viario central, reflejo de una voluntad urbanística precisa que organiza, a uno lado y al otro, las diferentes unidades domésticas en las que el 
trabajo del hierro se combina ahora con una actividad agrícola de autoconsumo.

Estamos, sin duda, ante un asentamiento ferrón que responde a una demanda procedente no sólo de la propia comunidad, sino de otras localidades del entorno, lo que refleja la existencia de una red comercial de cierto alcance por la que circularían igualmente productos cerámicos, cárnicos o de otro tipo (AZKARATE, SOLAUN, 2009:419-422). Cabe plantearse, incluso, la posibilidad de que el hierro de Bagoeta fuera distribuido en circuitos comerciales de mayor distancia, muy posiblemente hacia La Rioja y Navarra. Conservamos, por ejemplo, una tarifa de peaje dictada por Sancho Ramírez (I0761094) en la que, entre una lista de productos gravados a la entrada de Pamplona, se menciona el hierro importado a esta ciudad de manera regular y en grandes cantidades. Aunque no se explicita su origen en el documento, todo apunta a territorio alavés como lugar de procedencia (GAUTIER-DALCHE, 1982: 238).

Hay que señalar, además, la presencia por primera vez de una iglesia en el lugar ${ }^{29}$. A juzgar por su advocación -Santa Marina- no conviene llevar su origen más allá del siglo IX d.C. (GARCIA RODRIGUEZ, 1966, 198;AZKARATE, 1984). Ello no quiere decir, sin embargo, que su construcción coincidiera con el nacimiento del segundo emplazamiento, sino muy posiblemente con la aparición de los indicadores de poder más relevantes que cabe registrar en Bagoeta y que hay que llevar a fines del siglo $X o$ inicios de la centuria siguiente. Es en estas fechas, en efecto, cuando el asentamiento sufrirá una importante transformación que se manifiesta en la reorganización interna de las unidades domésticas, con ligeros desplazamientos del área residencial hacia espacios agrarios y de éstos hacia antiguos espacios construidos ${ }^{30}$. El resultado de esta reorganización espacial es un nuevo modelo de unidad doméstica perfectamente estructurada en tres áreas funcionales: una residencial situada en el centro de la parcela, otra agrícola emplazada a ambos lados de ésta y una última artesanal (siderometalúrgica) instalada en un extremo. Cambian además los modos constructivos, al introducirse los zócalos o muros de piedra sobre los que descansarían alzados de madera y/o barro amasado, suelos de arcilla al interior y cubiertas vegetales sustituidas en las últimas fases de ocupación por la teja.

No siempre resulta fácil identificar el agente - agentes causales que determinaron estos cambios. Existen, no obstante, datos suficientes como para reconocer la presencia de elites locales y subregionales, algunas de cierta entidad como Diego Beilaz quien, en el año $952^{31}$, cedía al monasterio de San Millán un importante número de bienes y siervos (hasta cuarenta casatos, dos de ellos residentes en Bagoeta). Como apuntó en su día J.A. García de Cortázar (1969: 109, 129) nos encontramos ante un potente alavés que, a juzgar por la ubicación de los bienes que posee, debió residir en la zona de Salinas de Léniz (que es lo mismo que decir en las cercanías de nuestro asentamiento). Tampoco sería inverosímil imaginar que los dos casatos de Bagoeta (Ulaquide Nunniz et Munnio Nunniz) pudieran ser dos de los ferrones que trabajaron en los complejos metalúrgicos descritos en el epígrafe anterior.

En definitiva, es en torno al año mil cuando convergen iglesia, racionalización urbana de los espacios habitados, movilización de importantes recursos con la creación de terrazas, aparición de la semiótica de la piedra, presencia de señores y casatos... indicadores todos ellos de un profundo cambio social que parece estar en la base de las transformaciones que documenta el registro arqueológico y que constituyen los argumentos sobre los que se articula este trabajo.

El asentamiento se mantendrá activo hasta el siglo XIV, momento en el cual será abandonado. El factor determinante de este súbito

\footnotetext{
29 Hoy convertida en ermita. Será objeto de excavación próximamente por el GPAC.

30 Muy posiblemente, como apunta Vigil-Escalera (2007: 266), "para aprovechar el mayor contenido orgánico de los espacios que antes tuvieron un uso residencial".

31 Cart. San Millán, n 48.
} 
proceso de decadencia apunta al interés de los señores alaveses por conseguir el monopolio sobre la producción de hierro, propósito que guarda una estrecha relación con otros factores estructurales como la propiedad de los bosques o la construcción de las grandes ferrerías hidráulicas en el norte alavés. Por la documentación generada en el contexto del llamado "Pacto de Arriaga" sabemos que en 1332 los cofrades de Arriaga solicitan que se prohiba la instalación de nuevas ferrerías en Álava, argumentado problemas de deforestación en los montes. Sin embargo, como apunta J.R. Diaz de Durana (1986: 225-230), esta demanda oculta un conjunto de intereses que van más allá de las preocupaciones por la deforestación. El principal, el que buscaba asegurar la propiedad sobre los montes, como se desprende también de la petición n 12: "Otrossi nos pidieron por merçet que les otorgassemos que los montes et seles et prados que ovieron fastaqui los fijosdalgo que los ayan segunt que los ovieron fasta aquí como dichos es,..." (apud DIAZ DE DURANA, 1986: 227). La protección y derechos sobre el bosque y la madera, unido a la construcción de ferrerías hidraúlicas en la cercana población de Legutiano durante la segunda mitad del siglo XIV (paradójicamente, por aquellos mismos señores que algunos años antes habían solicitado su prohibición) coadyuvaron en la desaparición de las viejas instalaciones siderometalúrgicas como Bagoeta, incapaces de subsistir ante la nueva coyuntura.

El despoblamiento del lugar, sin embargo, no supuso el abandono de las prácticas agrícolas y ganaderas en el mismo. Así cabe deducir de los pleitos que a principios del siglo XVI mantendrán los sucesores de los vecinos de Bagoeta desde sus nuevos hogares de Luko y Ullibarri Gamboa, por mantener la propiedad de las tierras de Laspagoeta, topónimo que recordaba la ya desaparecida aldea, transformada en un espacio de campos de cultivo y pasto que se ha conservado hasta prácticamente la actualidad.

\section{BIBLIOGRAFÍA}

ARGÜELLO, J.J., 1998, Minería y metalurgia férrica medieval en el Noroeste Peninsular. Aspectos técnicos y sociales, Técnicas agrícolas, Industriais e Constructivas na Idade Media, Vigo, pp. | 43-227.

AZKARATE, A. 1984, Epigrafía cristiana en tierras del Duranguesado: la inscripción de Santa Marina de Memaia (Elorrio, Vizcaya), Congreso de Estudios Históricos: Vizcaya en la Edad Media, Bilbao, pp. 347-355.

AZKARATE, A, SOLAUN, J.L., 2007, "Campillo Sur”, Arkeoikuska 2006, pp. 224-225.

AZKARATE, A., SOLAUN, J.L., 2009, Nacimiento y transformación de un asentamiento altomedieval en un futuro centro de poder: Gasteiz desde fines del siglo VII d.C. a inicios del segundo milenio, The archaeology of early medieval villages in Europe, Vitoria-Gasteiz, pp. 405-428.

AZKARATE, A., MARTÍNEZ, J.M., RODRIGUEZ, A., SOLAUN, J.L., 20I0, Despoblado de Bagoeta en Luko (Arrazua-Ubarrundia), Arkeoikuska 09, pp. 4I-47

BALLESTEROS, P., CRIADO, F., ANDRADE, J.M., 2006, Formas y fechas de un paisaje agrario de época medieval: A cidade da Cultura en Santiago de Compostela, Arqueología Espacial 26, pp. 193-226.

ETXEZARRAGA, I., 2004, Paleometalurgia del hierro en el País Vasco Cantábrico: las haizeolak. Un estado de la cuestión, Munibe 56, pp. 87-104.

EVE (Ente Vasco de la Energía), 1992, Inventario de indicios minerales de la cartografía geológica a escala 1:25.000 del País Vasco.

DIAZ DE DURANA, J.R., 1986, Álava en la Baja Edad Media. Crisis, recuperación y transformaciones socioeconómicas (c. 1 250- 1 525), Vitoria-Gasteiz.

FERNÁNDEZ CARVAJAL, J.A., 2008, Ferrerías de monte Callejaverde y Los Corcos (Monte de utilidad pública $n^{\circ}$ I 15 "Las Pozas"), Arkeoikuska 07, pp. 28I-284.

FERNÁNDEZ CARVAJAL, J.A., 2009, Ferrería de monte de Callejaverde", Arkeoikuska 08, pp. 300-302.

FRANCO PÉREZ, F. J., 2007, Nuevas propuestas de prospección arqueológica en la región cantábrica: el caso de las ferrerías de monte de Vizcaya, Territorio, Sociedad y Poder, 2, pp. 37-52.

GALETTI, P., 200 I, Uomini e case nel Medioevo tra Occidente e Oriente, Segrate.

GARCIA RODRIGUEZ, C., 1966, El culto de los santos en la España romana y visigoda, CSIC, Madrid.

GORROCHATEGUI, J.; YARRITU, M. J., 1 984, Prospecciones arqueológicas en Vizcaya durante 1983. Del Eneolítico a la Edad Media: asentamientos al aire libre, necrópolis y ferrerías de monte, Isturitz (Cuadernos de sección de Prehistoria-Arqueología), pp. 171-219.

GORROCHATEGUI, J. el alii, 1995, Paleometalurgia del hierro en Bizkaia. Las ferrerías de monte altomedievales, ler Simposi internacional sobre la Farga Catalana, Comunicacions. (Ripio, septiembre de 1993). 
LEROY, M., MERLUZZO, M., 1998, Les ateliers sidérurgiques médiévaux de Saint- Dizier (Haute-Marne), Bulletin de la Société Archéologique Champenoise, T. 91 , n 4, Reims.

LARRAZABAL GALARZA, J., 1997, Análisis de muestras siderometalúrgicas procedentes de los yacimientos Oiola II y Oiola IV (Trapaga-Bizkaia), Kobie (serie paleoantropología) 24, pp. 95-106.

LÓPEZ SÁEZ, J. A., LÓPEZ GARCÍA, P., BURJACHS, F. 2003. Arqueopalinología: Síntesis crítica. Polen, I2, pp. 5-35.

LÓPEZ SÁEZ, J.A., LÓPEZ MERINO, L. 2005. Precisiones metodológicas acerca de los indicios paleopalinológicos de agricultura en la Prehistoria de la Península Ibérica. Portugalia, 26, pp. 53-64.

MANNONI, T., GIANNICHEDDA, E., 2006, Arqueología. Materias, objetos y producciones, Barcelona.

McDONNELL, G., STARLEY, D., 2002, Excavation and Sampling Strategies for Metalworking Sites, HMS:Archaeology Data sheet No. 9 (http://www. hist-met.org). Año de consulta: 2010.

PEREDA GARCIA, I., 1992/93, La metalurgia prehidráulica del hierro en Bizkaia: el caso de los alrededores del pantano de Oiola (Trapagarán, Bizkaia), Kobie (serie paleoantropología) XX, pp. 109-122.

PEREDA GARCÍA, I., 1994, La metalurgia prehidráulica del hierro en Bizkaia: el caso de los alrededores del pantano de Oiola (Trapagarán, Bizkaia), Kobie (serie paleoantropología) XXI, pp. I09-122.

PEREDA GARCIA, I., 1997, Aportación al conocimiento de la metalurgia del hierro en los S. XI-XIII en Bizkaia: el yacimiento de Oiola - IV (Trapagarán, Bizkaia), Kobie (serie paleoantropología) XXIV, pp. 69-93.

PLATA MONTERO, A., SAIZ ALONSO, S., BENEDET, V., 2010, Correría, I4I, Palacio Maturana-Verástegui o del Marques el Fresno, Arkeoikuska 2009, pp. I46- I 47.

QUIROS CASTILLO, J.A., 2009a, Arqueología de los espacios agrarios medievales en el País Vasco, Hispania, vol. LXIX, n. 233, pp. 619-652.
QUIROS CASTILLO, J.A., 2009b, Arqueología del campesinado altomedieval: las aldeas y las granjas del País Vasco, The archaeology of early medieval villages in Europe, Vitoria-Gasteiz, pp. 385-403.

QUIROS CASTILLO, J.A., 2010, La arqueología de las aldeas en el noroeste peninsular. Comunidades campesinas y poderes territoriales en los siglos V-X, Monasterios, espacio y sociedad en la España cristiana medieval, $\mathrm{XX}$ Semana de Estudios Medievales, Nájera, del 3 al 7 de agosto de 2009, Logroño, pp. 225-256.

QUIROS, J.A., VIGIL-ESCALERA, A., 2007, Networks of peasant villages between Toledo and Velegia Alabense, northwestern Spain (V-Xth centuries), Archeologia Medievale XXXIII, pp. 79-I28.

SOLAUN BUSTINZA, J.L., 2005, La cerámica medieval en el País Vasco (siglos VIII-XIII), Vitoria-Gasteiz.

SOLAUN, J.L., ESCRIBANO, S., 2006, Aproximación a la caracterización y organización de la producción cerámica bajomedieval en Vitoria-Gasteiz (siglos XIV-XV), Estudios de Arqueología Alavesa 23, pp. 227-286.

STARLEY, D., 1995, Hammerscale, HMS: Archaeology Data sheet No. 10 (http://www. hist-met.org). Año de consulta: 2010.

TYLECOTE, R.F., 1981, The medieval smith and his methods, Medieval industry, CBA Research Report, $\mathrm{n}^{\circ}$ 40, pp. 42-50.

TYLECOTE, R.F., 1987, The early history of metallurgy in Europe, New York.

UBIETO ARTETA, A., 1976, Cartulario de San Millán de la Cogolla (759-1076), Valencia.

VIGIL-ESCALERA, A., 2007, Granjas y aldeas altomedievales al norte de Toledo (450-800 d.C.), Archivo Español de Arqueología, vol. 80, pp. 239-284.

ZAGARI, F., 2005, II metallo nel Medievo. Tecniche Strutture Manufatti, Roma. 


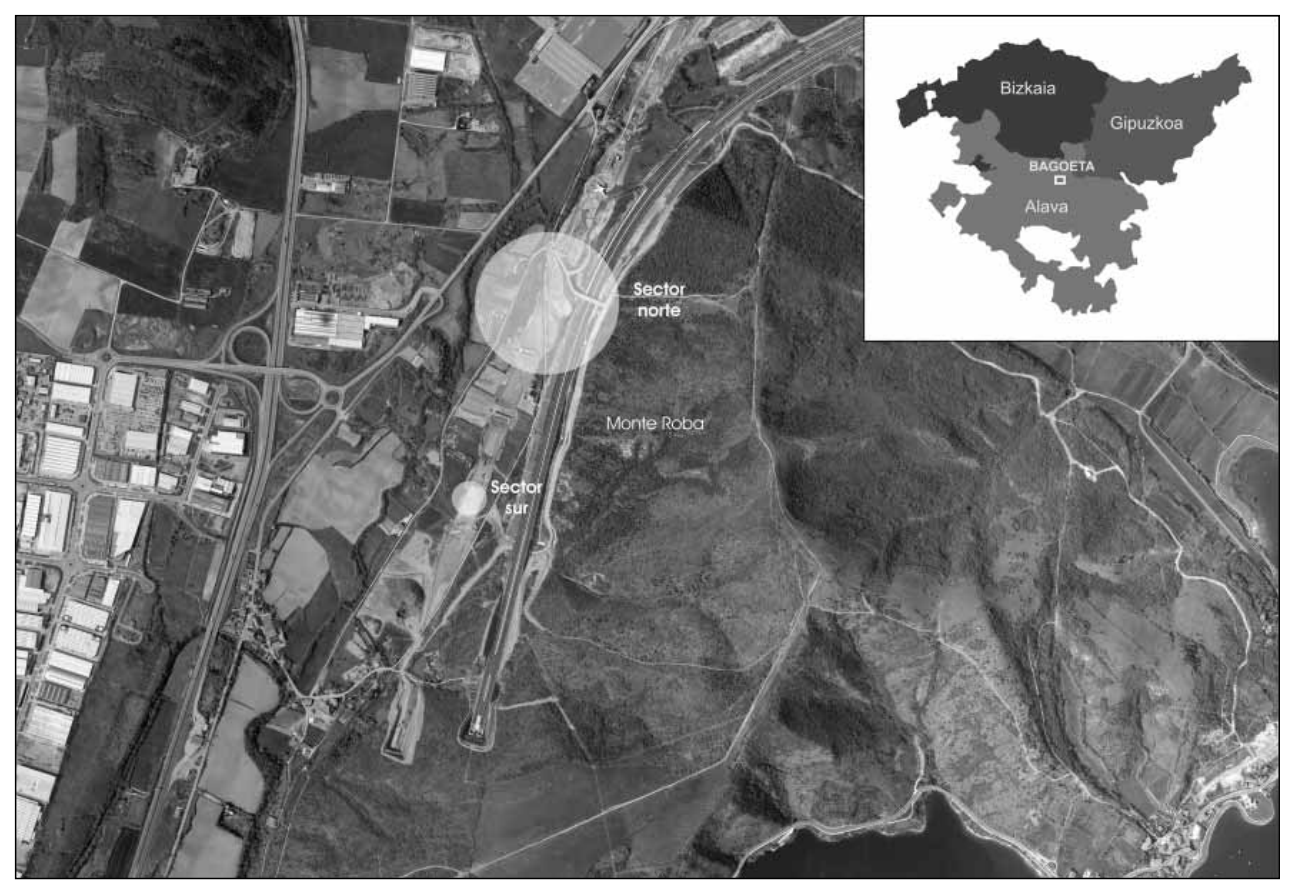

Figura I. Mapa de situación del yacimiento de Bagoeta con los dos sectores documentados.

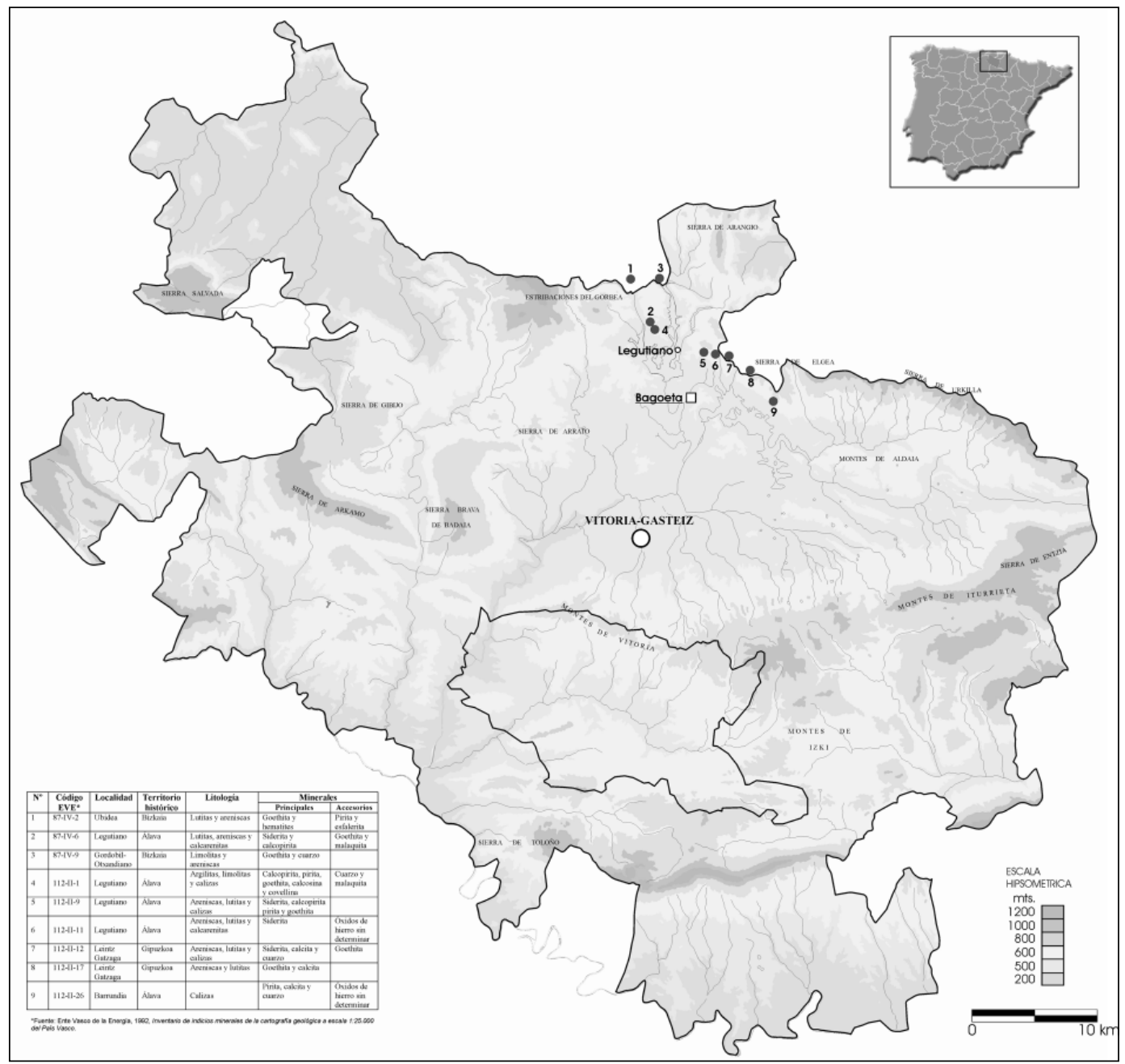

Figura 2. Mapa de indicios mineros existentes en las inmediaciones de Bagoeta (fuente: Ente Vasco de Energía). 


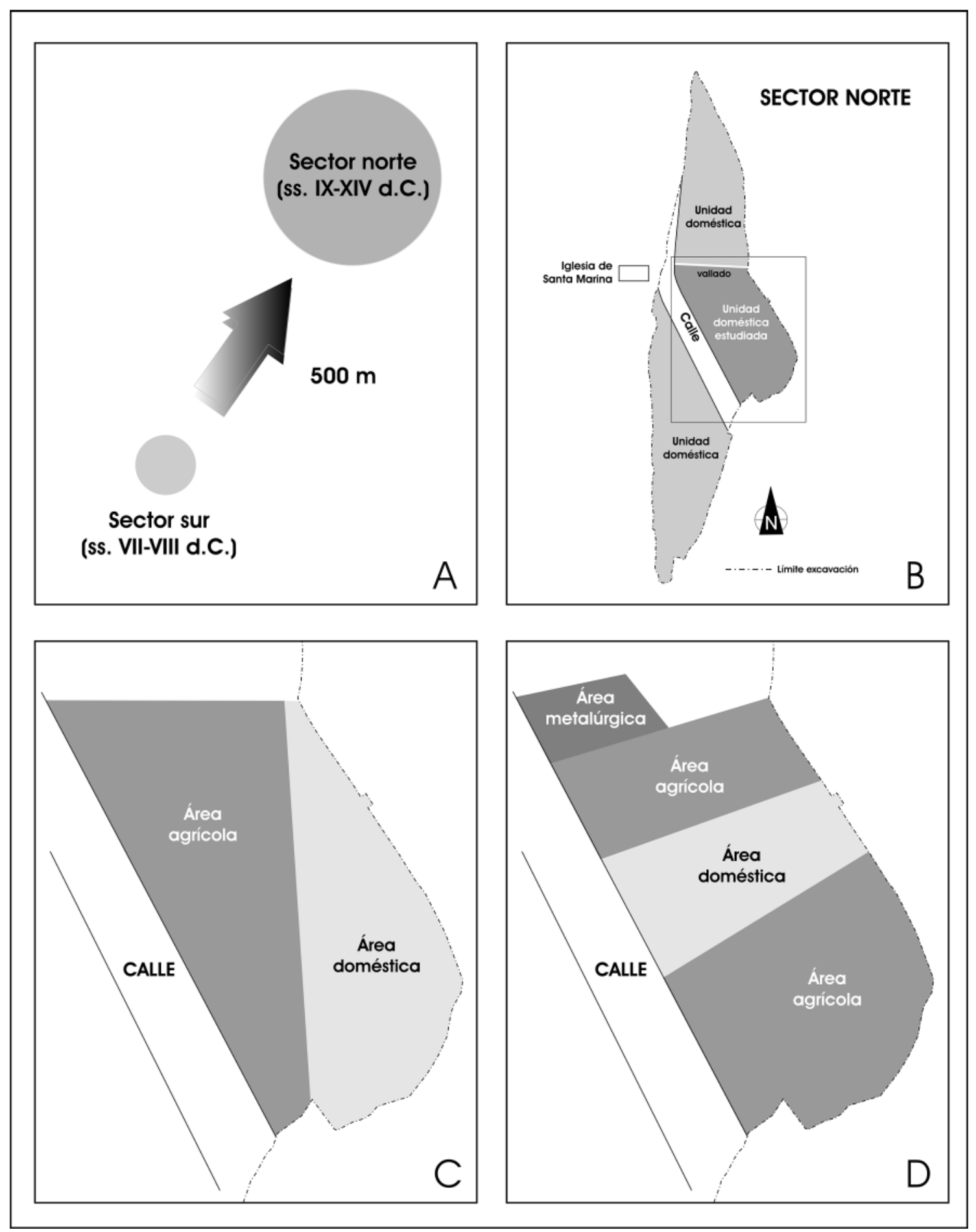

Figura 3. A) Desplazamiento al sector norte en el siglo IX. B) Área excavada en el sector norte y ubicación de las tres unidades domésticas detectadas. C) Articulación de los espacios en la unidad doméstica central durante su primera fase. D) Articulación de los espacios en la unidad doméstica central durante su segunda fase. 


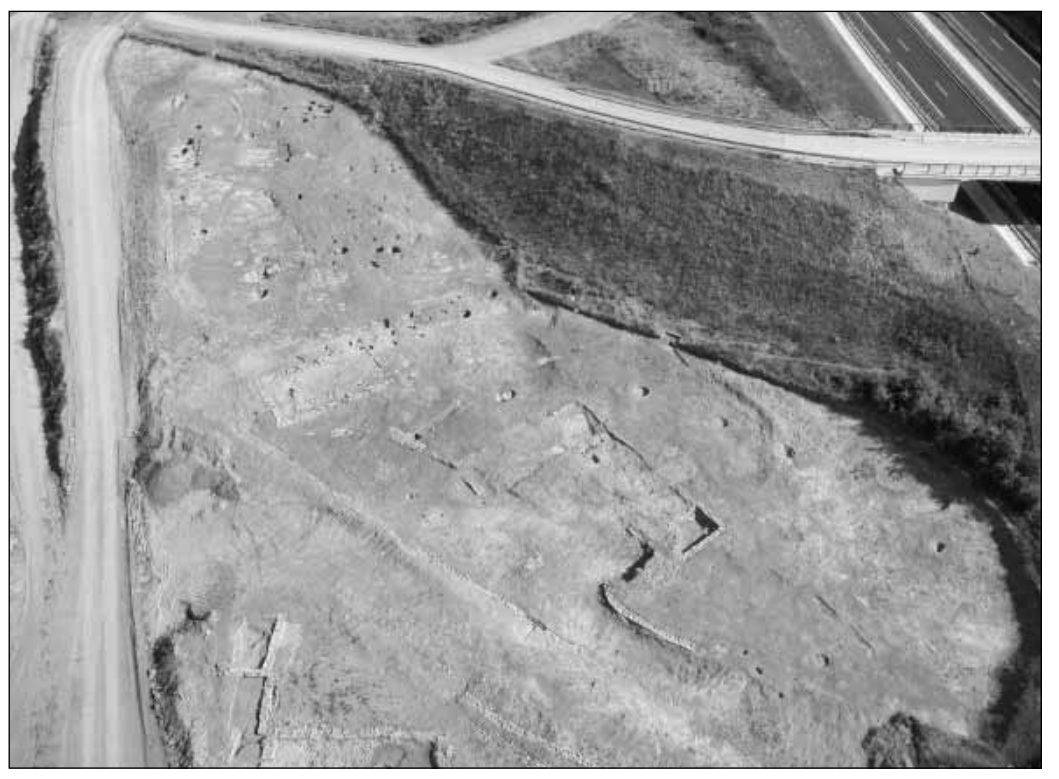

Figura 4. Vista aérea del sector norte con la unidad doméstica estudiada en primer término.

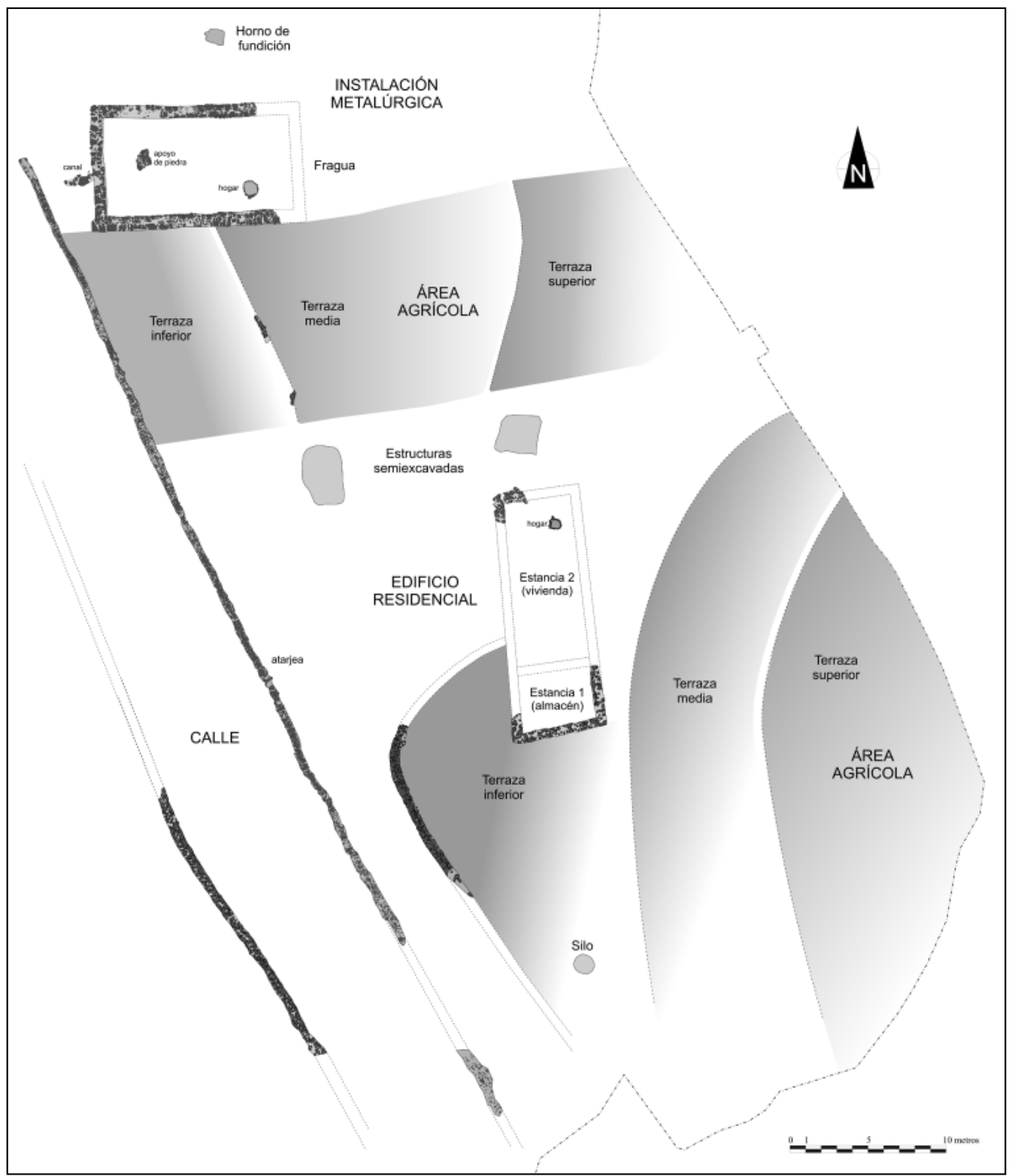

Figura 5. Organización espacial, durante los siglos XI y XII, de la unidad doméstica estudiada. 


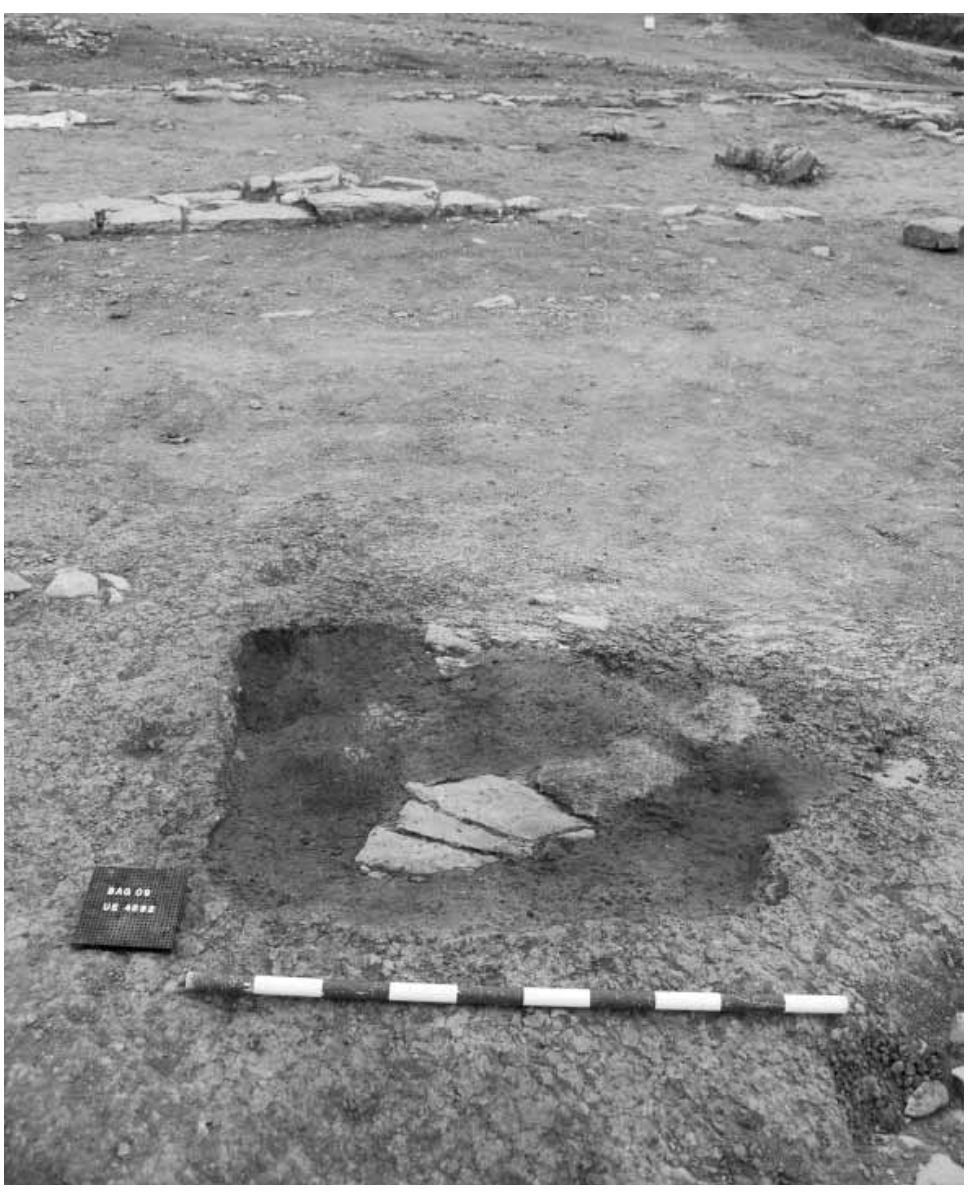

Figura 6. Fondo de la cubeta de reducción del horno, completamente rubefactado, con el edificio de la fragua inmediatamente detrás.

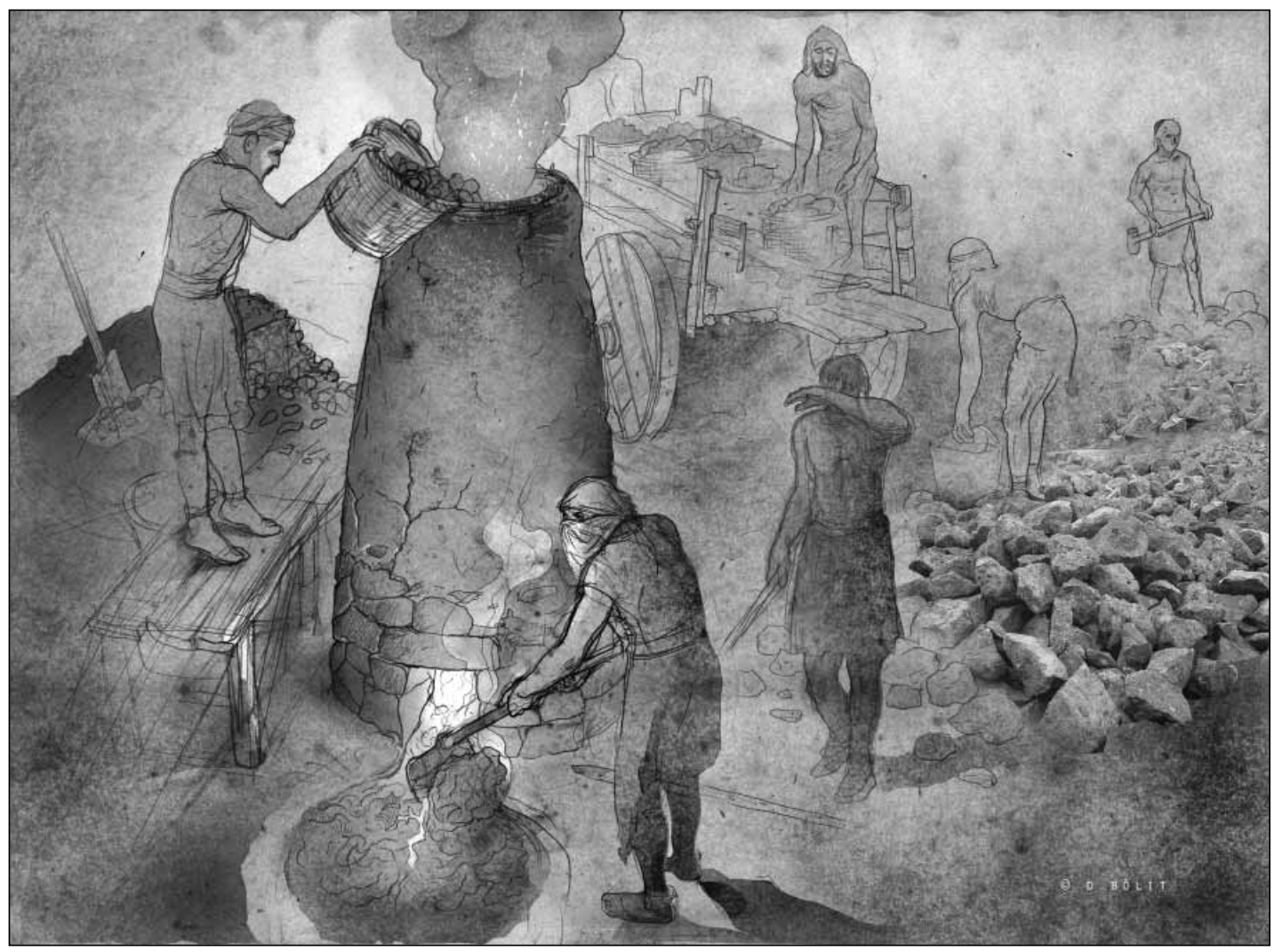

Figura 7. Reconstrucción del trabajo metalúrgico en un horno similar a los registrados en Bagoeta. 


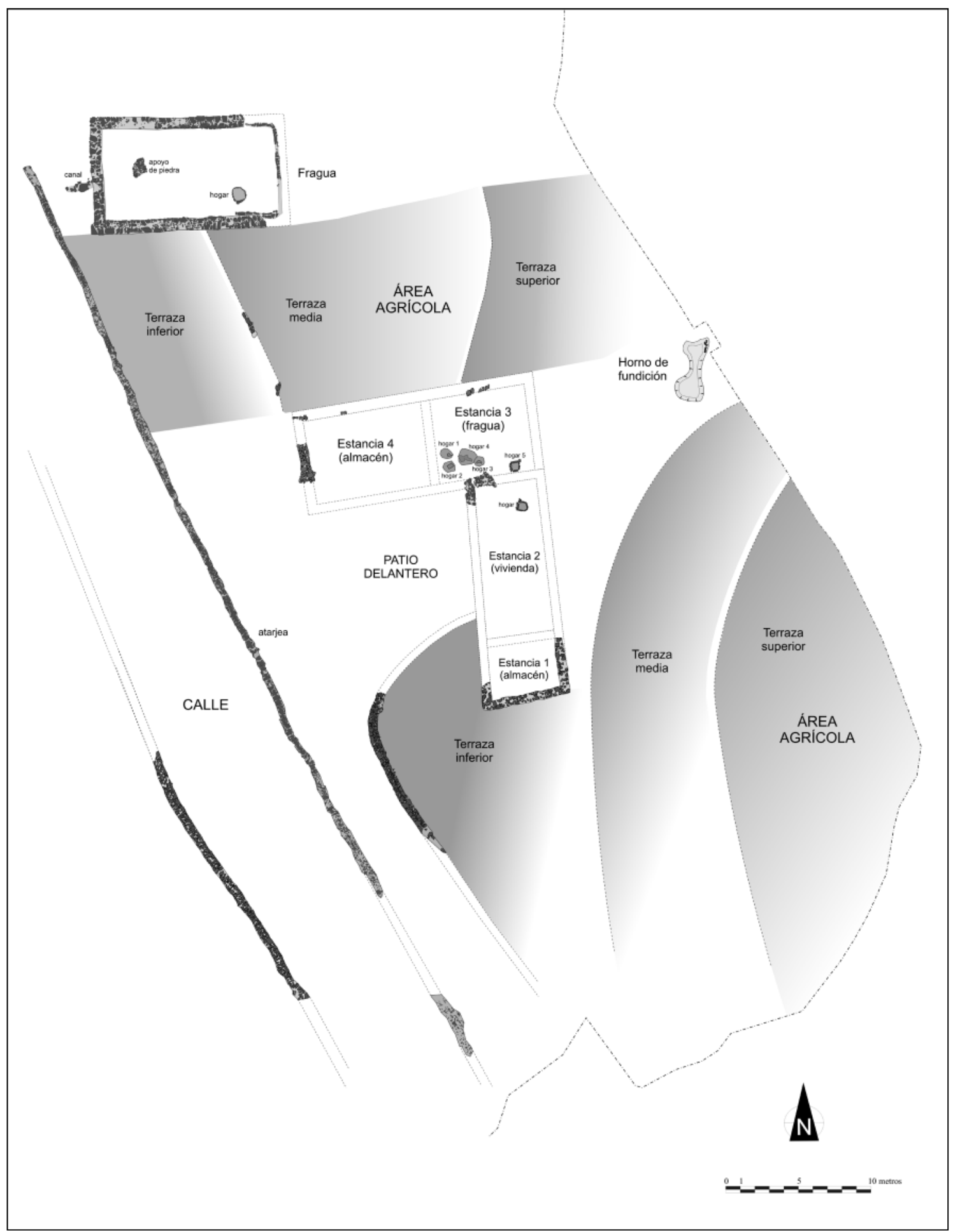

Figura 8. Organización espacial de la unidad doméstica estudiada, tras las reformas del siglo XIII. 